\title{
Therapeutic effects of kinesio taping in children with cerebral palsy: a systematic review
}

\author{
Joaquin Ortiz Ramírez, B.S. in Physical Therapy and Sagrario Pérez de la Cruz, M.D. ${ }^{a}$
}

\begin{abstract}
Pediatric cerebral palsy is a non-progressive neurological disorder. It is one of the most common causes of disability among children. Numerous physical therapy techniques are currently used for treatment, and kinesio taping is one of them. The main objective of this study was to review the outcomes of using kinesio taping in published scientific studies conducted in pediatric patients with cerebral palsy and determine their methodological quality.

The main scientific databases and the studies published in the official site of the Asociacion Española de Vendaje Neuromuscular (Spanish Association for Neuromuscular Taping) were reviewed.

Nine studies were included, which provided important outcomes. These studies show the effectiveness of recovering upper limb and motor function and solving dysphagia, which could be present in these patients, although scientific evidence may expand due to improvements in methodology.

Key words: kinesio taping, function recovery, cerebral palsy, pediatrics, swallowing.
\end{abstract}

http:/ / dx.doi.org/10.5546/aap.2017.eng.e356

To cite: Ortiz Ramírez J, Pérez de la Cruz S. Therapeutic effects of kinesio taping in children with cerebral palsy: a systematic review. Arch Argent Pediatr 2017;115(6):e356-e361.

\section{INTRODUCTION}

Pediatric cerebral palsy $(\mathrm{CP})$ is a

a. School of

Health Sciences,

Universidad de

Almería. La Cañada

de San Urbano,

Almería, Spain.

E-mail address:

Sagrario Pérez de la

Cruz, M.D.:

spd205@ual.es

Funding:

None.

Conflict of interest:

None.

Received: 3-2-2017

Accepted: 6-27-2017
Numerous physical therapy techniques are currently used for the treatment of motor and non-motor alterations in these patients. These common treatments include botulinum toxin, serial splints, orthopedic surgery and/or orthesis. These interventions are somewhat invasive and designed to act at a peripheral level, but do not promote normal central motor development. At present there is also another method available called kinesio taping (KT) or neuromuscular bandage.

Kinesio tape is the name of an adhesive tape created by Kenzo Kase in Japan in 1973. ${ }^{6}$ Over the past years, the concept of KT has spread extensively, and was designed to mimic the elasticity of human skin (in terms of weight and thickness).

The tape is completely made of cotton with an anti-allergic adhesive layer that allows for evaporation and quick drying. These properties make it resistant and wearable for a long period, in general, 3 to 5 days at a time; it is even water resistant. The tape has an elasticity of up to $140 \%$, equal to that of human skin. The tape may be applied in different ways, such as the following: I shape (the strips are placed in the area above the muscle belly), Y shape (surrounding the muscle belly), $X$ shape (from a central point surrounding the muscle belly), octopus shape (for lymph drainage), donut shape (to increase space) or star shape (to increase central space). ${ }^{6,7}$

The creator of this technique described its therapeutic effects, which will depend on the extent to which the tape is stretched and the shape of application. ${ }^{7,8}$ Given that it may be applied on any muscle or joint, ${ }^{9}$ and knowing the potential influence in the regulation of muscle tone, the tape 
is being applied in the sports field to improve performance and / or prevent injuries. ${ }^{10,11} \mathrm{It}$ has also been used successfully in the field of orthopedics, traumatology, and sports. In the past years, new applications have emerged in the field of neurology, ${ }^{12-14}$ rheumatology, ${ }^{15,16}$ and even urogynecology; $;^{17,18}$ and have shown effects never described before, such as improving sensory feedback, which have yet to be demonstrated by scientific evidence. Likewise, comparative studies have been made between the effects of KT and other taping modalities already in place for many years. ${ }^{19,20}$

However, and in spite of its popularity, few scientific studies have been conducted to support KT use. The effects initially attributed to KT are still controversial and there is not sufficient scientific evidence to support them, such as its tonic or relaxing effect on the increase of mechanoreceptor stimulation, its effect on fascial tissue, its effect to reduce pressure under the skin, facilitating blood flow to painful areas, its anti-inflammatory or anti-edematous effect due to its action on exteroceptive and proprioceptive receptors. ${ }^{21}$

What is being advocated about KT is that, together with other therapeutic interventions, it may promote a comprehensive rehabilitation process, increasing autonomy to perform BADL and improving their quality.22

The main objective of this study was to review the outcomes of using KT in published scientific studies conducted in pediatric patients with $\mathrm{CP}$ and determine their methodological quality.

\section{METHODOLOGY}

A bibliographic search was done in the following databases: Medline, Ovid, Cinahl, Pedro, Scopus, The Cochrane Library, EMBASE, Science Direct, Índice Médico Español (Spanish
Medical Index, IME), and the official site of the Asociación Española de Vendaje Neuromuscular (Spanish Association for Neuromuscular Bandage, AEVNM).

Key words included kinesiotape, kinesio tape, tape, kinesiotaping, taping, KT, cerebral palsy, cerebral palsy physical therapy, cerebral palsy children. In addition, shortened words were searched to include any variations used in the bibliography. Terms were also combined.

Limitations applied to databases included publications written in English, French, Portuguese, and Spanish, and studies conducted on humans. In addition, we decided not to limit the publication period because this topic has been studied for several years in English-speaking countries but in Spain it is only emerging, so as not to leave out any valuable study for this review (inclusion and exclusion criteria are described in Table 1).

Manual searches were also done in electronic journals which were considered more relevant for the topic under study. Other searches were also done applying the snowballing technique, reviewing the references of articles already included for review in this study to verify if there were additional articles not found in the databases.

To analyze the internal validity of studies, section A (screening and detailed questions) of the Critical Appraisal Skills Programme (CASP) guidelines was used to make a critical reading of clinical trials (Table 2). These guidelines are made up of 11 questions grouped into three sections. The CASP guidelines serve to quickly obtain useful information about the methodological quality of clinical trials, thus enabling to make a critical appraisal. The score assigned to each selected study shows its methodological quality. Based on the type of study (in our case,

TABLE 1. Inclusion and exclusion criteria

\begin{tabular}{ll}
\hline INCLUSION CRITERIA & EXCLUSION CRITERIA \\
\hline - Language: English, Spanish, French, and Portuguese. & - Gray literature and editorial comments. \\
- Publication period: no limitations. & Participants with associated diseases interfering \\
- Characteristics of the population: pediatric subjects & $\begin{array}{l}\text { with study outcomes. } \\
\text { diagnosed with cerebral palsy. }\end{array}$ \\
- Type of intervention: use of KT for physical therapy, \\
either alone or together with other non-surgical treatments. \\
- $\begin{array}{l}\text { Original studies (qualitative, quantitative, combined), } \\
\text { bibliographic reviews, and single case studies. }\end{array}$
\end{tabular}


treatment), the level of evidence ranges from I (randomized, controlled clinical trials [RCTs] and meta-analysis), II (cohort studies and low-quality RCTs), III (case-control studies), IV (low-quality case series, cohort studies, or case-control studies) to $\mathrm{V}$ (expert opinion).

The Jadad scale has also been used to assess the quality of clinical trials; it assigns a maximum score of 5 (maximum methodological quality) and a minimum of 0 . The questions are based mainly on internal validity assessment, outcome significance, and practical value given that it is necessary to consider study outcome validity together with clinical relevance and feasibility. All questions provide affirmative, intermediate or negative answers. Negative answers detract validity and applicability from results and the recommendations made by the authors (Table 3 ).

\section{RESULTS}

A total of 480 articles were identified in the different databases and through the AEVNM. In relation to the year of publication, a significant increase in KT studies was observed in recent years; 2012 and 2014 were the years with the highest number of publications.

Fifteen potentially valid publications were found in relation to the use of KT in the field of neurology, without specifications. Once selection and methodological quality criteria were applied and these studies were analyzed in detail, a total of 7 articles were accepted for inclusion because they met all inclusion criteria described above.
Table 3 shows a summary of the main studies included in the review.

\section{DISCUSSION}

Not many studies have been conducted on the use of KT for the treatment of pediatric patients with CP. Studies on its effectiveness have been conducted only in recent years (2006-2016).

Out of the 7 articles included in this review, 2 attempted to demonstrate the effectiveness of $\mathrm{KT}$ on motor function of children with $\mathrm{CP} ;{ }^{23,24}$ 2 had the objective of measuring KT effectiveness to improve ptyalism in these children;, ${ }^{25,26} 1$ was about the effect of KT on hand function; ${ }^{27}$ 1 studied the effect of KT on genu recurvatum ${ }^{28}$ shown by some children with $\mathrm{CP}$; and the last article attempted to measure the effectiveness of KT on upper limb function in these children. ${ }^{29}$

The 2 studies focused on measuring KT effectiveness on motor function of children with $\mathrm{CP}$ showed no statistically significant results. Both Kaya Kara O et al..$^{23}$ and Simsek TT et al..$^{24}$ included a control group and an experimental group. Results were assessed in a similar manner: both authors used the Functional Independence Measure for Children (WeeFIM) and the Gross Motor Function Measure (GMFM). Simsek TT et al. ${ }^{24}$ also assessed the sitting position using the Sitting Assessment Scale (SAS) and found significant differences in body alignment. Both studies used similar samples and durations. Also, both found improvements but failed to meet the proposed objectives. The main problem of not finding results to support

TABLE 2. Sections of the CASP guidelines

Section A: Are the results of the trial valid?

Screening questions:

- Did the trial address a clearly focused issue?

- Was the assignment of patients to treatments randomized?

- Were all of the patients who entered the trial properly accounted for at its conclusion?

Detailed questions:

- Were patients, health workers and study personnel "blind" to treatment?

- Were the groups similar at the start of the trial?

- Aside from the experimental intervention, were the groups treated equally?

Section B: What are the results?

- How large was the treatment effect?

- How precise was the estimate of the treatment effect?

Section C: Will the results help locally?

- Can the results be applied in your context or to the local population?

- Were all clinically important outcomes considered?

- Are the benefits worth the harms and costs? 
the effectiveness of KT was the short period of time assigned to the study because both studies were conducted over a 3-month period only. It is necessary to develop future studies with larger samples and longer periods because rehabilitation in these patients is sometimes slow, and it takes time to assess whether $\mathrm{KT}$ is effective or not.

Another common problem in these children is ptyalism, because excessive salivation causes impaired speech and trouble eating ${ }^{25}$ which lead to different psychosocial problems. Ptyalism is a condition that affects the quality of life of these patients. KT is applied to the anterior muscles of the neck and face, thus helping to recover motor control, strengthening muscles and helping with laryngeal elevation. Other authors, such as Caneschi WF et al. ${ }^{25}$ and Tello CL et al., ${ }^{26}$ found significant differences in their results, so it may be stated that KT is an adequate tool for the management of ptyalism. These studies reported that the adhesive tape acts as a continuous stimulus through cutaneous innervation in the suprahyoid region of the neck, therefore providing feedback and perceptive information. However, it is necessary to mention that these studies did not use validated scales but measured drooling frequency, skin irritation, unpleasant smell, need to clean patients' chin, difficulty feeding, and need to change patients' bibs and clothes; all these outcome measures are highly subjective and were assessed by patients' family members or caregivers. Future studies need to use validated scales to obtain objective results and provide greater validity to investigations, and if they do not include a control group with another treatment, time alone does not provide internal validity to the studies.

Fine motor impairment is common among children diagnosed with CP due to the alterations in their upper limb position. In the study conducted by Keklicek $\mathrm{H}$ et al., ${ }^{27}$ children had a pattern of internal rotation in the upper limbs, with elbow flexion, forearm pronation, wrist flexion, finger flexion, and thumb-in-palm deformity. In this study, children were randomly assigned to 2 groups (a control group and an

TABLE 3. Summary table of selected articles

\begin{tabular}{|c|c|c|c|c|c|c|}
\hline Author(s) & $\begin{array}{l}\text { Year of } \\
\text { ublication }\end{array}$ & Objective & $\begin{array}{l}\text { Sample } \\
\text { Age }\end{array}$ & $\begin{array}{l}\text { Sample } \\
\text { distribution }\end{array}$ & $\begin{array}{r}\mathrm{CA} \\
\mathrm{J}\end{array}$ & $\begin{array}{c}\text { Quality } \\
\text { (CASP guidelines)/ } \\
\text { JADAD scale }\end{array}$ \\
\hline Keklicek H, et al. ${ }^{27}$ & 2015 & $\begin{array}{l}\text { To assess the effect } \\
\text { on hand function }\end{array}$ & $\begin{array}{c}\quad 45 \\
\text { Age: } 4-14\end{array}$ & $\begin{array}{l}2 \text { groups. } \\
\text { G1: assessment with } \\
\text { and without KT; } \\
\text { G2: without KT }\end{array}$ & Effective & $\mathrm{II} / 3+$ \\
\hline Kaya Kara O, et al. ${ }^{23}$ & 2014 & $\begin{array}{l}\text { To assess the effect } \\
\text { on function and } \\
\text { autonomy }\end{array}$ & $\begin{array}{c}30 \\
\text { Age: } 7-14\end{array}$ & $\begin{array}{l}2 \text { groups. } \\
\text { G1: KT; } \\
\text { G2: without KT }\end{array}$ & $\begin{array}{l}\text { Not effective in the } \\
\text { long term but with } \\
\text { improvements } \\
\text { in the short term }\end{array}$ & II $/ 4$ \\
\hline Caneschi WF, et al. ${ }^{25}$ & 2014 & $\begin{array}{l}\text { To assess the effect } \\
\text { on ptyalism }\end{array}$ & $\begin{array}{c}11 \\
\text { Age: } 5-10\end{array}$ & 1 group & Effective & $\mathrm{IV} / 2$ \\
\hline Ghalwash AM, et al. ${ }^{28}$ & $28 \quad 2012$ & $\begin{array}{l}\text { To assess the effect } \\
\text { on genu recurvatum }\end{array}$ & $\begin{array}{c}14 \\
\text { Age: } 5-7\end{array}$ & $\begin{array}{l}2 \text { groups. } \\
\text { G1: KT + physical } \\
\text { therapy; } \\
\text { G2: knee brace + } \\
\text { + therapy }\end{array}$ & $\begin{array}{l}\text { Not effective, } \\
\text { but with } \\
\text { improvements } \\
\text { in function }\end{array}$ & III $/ 4$ \\
\hline Tello CL , et al. ${ }^{26}$ & 2012 & $\begin{array}{l}\text { To assess the effect } \\
\text { on swallowing }\end{array}$ & $\begin{array}{c}10 \\
\text { Age: } 9 \pm 8,76\end{array}$ & 1 group & Effective & $\mathrm{IV} / 2+$ \\
\hline Simsek TT, et al. ${ }^{24}$ & 2011 & $\begin{array}{l}\text { To assess the effect } \\
\text { on function and } \\
\text { autonomy }\end{array}$ & $\begin{array}{c}31 \\
\text { Age: } 8 \pm 4\end{array}$ & $\begin{array}{l}2 \text { groups. } \\
\text { G1: physical } \\
\text { therapy + KT; } \\
\text { G2: physical therapy }\end{array}$ & $\begin{array}{c}\text { Not effective, but } \\
\text { with improvements } \\
\text { in body alignment }\end{array}$ & III $/ 4$ \\
\hline Yasukawa A, et al. ${ }^{29}$ & 2006 & $\begin{array}{l}\text { To assess the effect } \\
\text { on function of } \\
\text { upper limbs }\end{array}$ & $\begin{array}{c}15 \\
\text { Age: } 4-16\end{array}$ & 1 group & Effective & $\mathrm{IV} / 2$ \\
\hline
\end{tabular}

KT: kinesio tape. CASP: Critical Appraisal Skills Programme. G: group. 
experimental group). Significant differences were observed between both groups over the period of the activity; therefore, according to the outcomes of this study, it may be inferred that $\mathrm{KT}$ is adequate to reduce spasticity and improve proprioception. The objective of the article by Yasukawa A et al. ${ }^{29}$ was to measure $\mathrm{KT}$ effectiveness on upper limb function because children with a poor shoulder alignment have a greater difficulty to lead an autonomous life. In this study, results were assessed using the Melbourne scale, which measures quality of upper limb movement while reaching, grasping, and handling. Results were satisfactory and showed an improvement in movement control and quality. KT may be considered an adequate complement for the management of upper limb control and function in pediatric patients with $\mathrm{CP}$.

Another common alteration observed in a large number of children with spastic CP is genu recurvatum, which is a deformity in the tibiofemoral joint where the range of movement exceeds 0 degrees of extension. It is caused by excessive activity of the muscles in the posterior and distal portions of the leg. ${ }^{30}$ The study by Ghalwash AM et al. ${ }^{28}$ attempted to measure KT effectiveness on genu recurvatum control but no statistically significant differences were observed between the two groups, so it was not possible to determine that KT was effective for this indication. The study did find an improvement in motor function of children as measured by the GMFM. Studies with a larger sample size are required because only 14 children were included in this study and, based on such small sample, it is very difficult to obtain conclusive data to determine whether KT is effective or not.

The studies conducted by Keklicek $\mathrm{H}$ et al., ${ }^{27}$ Caneschi WF et al., ${ }^{25}$ Tello CL et al., ${ }^{26}$ and Yasukawa A et al. ${ }^{29}$ found favorable results regarding the effectiveness of KT on the treatment of ptyalism, upper limb function, and hand function among children with CP. Other studies, such as the one by Kaya Kara $\mathrm{O}$ et al., ${ }^{23}$ failed to meet their objectives regarding improved function and autonomy but found short-term improvements. The study by Ghalwash AM et al. ${ }^{28}$ did not demonstrate the effectiveness of KT to improve genu recurvatum but showed satisfactory results on function in these children. Whereas the study by Simsek TT et al. ${ }^{24}$ found no statistically significant results to support the effectiveness of $\mathrm{KT}$ on motor function of children with $\mathrm{CP}$, it showed that it improved body alignment.
The studies conducted to date have several limitations. For results to be extrapolated to all pediatric patients with $\mathrm{CP}$, it is necessary to conduct studies with a larger number of participants so that conclusive results and sufficient scientific evidence are obtained. The mean number of subjects included in the 7 studies about pediatric $\mathrm{CP}$ was 22 , which should be larger in future studies. If case series or case-control studies fail to estimate the sample size necessary to establish significant differences, it will not be possible to obtain sufficient scientific evidence from them.

The period assigned to studies should also be extended to confirm long-term effectiveness of KT. The only study with an adequate study period was the one by Tello CL et al., ${ }^{28}$ which lasted 7 months. These patients require a long time for rehabilitation because most of them show improvements in the long term. However, if there is no control group using a different treatment, time alone does not provide internal validity to the studies; therefore, it would be difficult to confirm whether KT is effective or not in the long term.

A better description of how KT was applied in each study is required to determine its effectiveness in each case. In this review, only the studies by Tello CL et al. ${ }^{26}$ and Simsek TT et al. ${ }^{24}$ included an adequate description of KT application.

\section{CONCLUSION}

Most outcome measures observed in the studies included in this review showed the benefits of KT; however, from the stance of scientific evidence and methodological quality, studies have not been conclusive. It is necessary to define standard criteria to demonstrate the effects of $\mathrm{KT}$ because there is no clear consensus on the basic aspects of KT, such as the duration of tape application or the extent of stretching used.

\section{REFERENCES}

1. Hielkema T, Hadders-Algra M. Motor and cognitive outcome after specific early lesions of the brain: a systematic review. Dev Med Child Neurol 2016;58(4):46-52.

2. Lorente-Hurtado I. La parálisis cerebral. Actualización del concepto, diagnóstico y tratamiento. Pediatr Integral 2007;11(8):687-98.

3. Sanger TD. Movement Disorders in Cerebral Palsy. J Pediatr Neurol 2015;13(4):198-207.

4. Pascual JM, Koenigsberger MR. Parálisis cerebral: factores de riesgo prenatales. Rev Neurol 2003;37(3):275-80.

5. Wright M, Wallman L. Cerebral Palsy. In: Campbell SK, Palisano RJ, Orlin MN. Physical therapy for children. 4 ed. Missouri: Elsevier-Sanders; 2012:577-627. 
6. Kase K, Wallis J, Kase T. Clinical therapeutic applications of the Kinesiotaping method. 2nd ed. Tokyo: Ken Ikai; 2003.

7. Kahanov L. Kinesio taping: An overview of use with athletes, part II. Athl Ther Today 2007;12(4):5-7.

8. Thelen MD, Dauber JA, Stoneman PD. The clinical efficacy of kinesio tape for shoulder pain: a randomized, double-blinded, clinical trial. J Orthop Sports Phys Ther 2008;38(7):389-95.

9. Cools A, Witvrouw E, Danneels L, et al. Does taping influence electromyographic muscle activity in the scapular rotators in healthy shoulders? Man Ther 2007;7(3):154-62.

10. Halseth T, McChesney JW, DeBeliso M, et al. The effects of Kinesio ${ }^{\mathrm{TM}}$ taping on proprioception at the ankle. J Sports Sci Med 2004;3(1):1-7.

11. May K. Kinesio tape: A better alternative for many applications. Training \& Conditioning 2008;18:126.

12. Yang SR, Heo SY, Lee HJ. Immediate effects of kinesio taping on fixed postural alignment and foot balance in stroke patients. J PhysTher Sci 2015;27(11):3537-40.

13. Heo SY, Kim KM. Immediate effects of Kinesio Taping on the movement of the hyoid bone and epiglottis during swallowing by stroke patients with dysphagia. J Phys Ther Sci 2015;27(11):3355-57.

14. Lee DH, Kim WJ, Oh JS, et al. Taping of the elbow extensor muscle in chronic stroke patients : comparison between before and after three-dimensional motion analysis. J Phys Ther Sci 2015;27(7):2101-3.

15. ŻukB,Księżopolska-OrłowskaK. Usefulness of Kinesiology Taping method in inflammatory rheumatic illnesses in childhood. Reumatologia 2008;46(6):340-7.

16. Kocyigit F, Turkmen MB, Acar M, et al. Kinesio taping or sham taping in knee osteoarthritis?A randomized, doubleblind, sham-controlled trial. Complement Ther Clin Pract 2015;21(4):262-7.

17. Reyhan AÇ, Dereli EE, Çolak TK. Low back pain during pregnancy and kinesio tape application. J Back Musculoskelet Rehabil 2017;30(3):609-13.

18. Do ES, Park KM, Lee SH. A Study on the Effects of the Kinesio Tape Method on Perimenstrual Discomforts. J Korean Community Nurs 2003;14(3):415-23.
19. Bayrakci Tunay V, Akyüz A, Önal S, et al. Comparison of the instant effects of kinesio and McConnell patellar taping on performance in patellofemoral pain syndrome. Fizyoterapi Rehabilitasyon 2008;19(3):104-9.

20. Briem K, Eythörsdöttir H, Magnúsdóttir RG, et al. Effects of the kinesio tape compared with nonelastic sports tape and the untaped ankle during a sudden inversion perturbation in male athletes. J Orthop Sports Phys Ther 2011;41(5):328-35.

21. Karadag-Saygi E, Cubukcu-Aydoseli K, Kablan N, et al. The role of kinesiotaping combined with botulinum toxin to reduce plantar flexors spasticity after stroke. Top Stroke Rehabil 2010;17(4):318-22.

22. Espejo-Antúnez L , Apolo-Arenas MD. Revisión bibliográfica de la efectividad del kinesiotaping. Rehabilitación 2011;45(2):148-58.

23. Kaya Kara O, Atasavun Uysal S, Turker D, et al. The effects of Kinesio Taping on body functions and activity in unilateral spastic cerebral palsy: a single-blind randomized controlled trial. Dev Med Child Neurol 2015;57(1):81-8.

24. Şimşek TT, Türkücüoğlu B, Çokal N, et al. The effects of Kinesio(R) taping on sitting posture, functional independence and gross motor function in children with cerebral palsy. Disabil Rehabil 2011;33(21-22):2058-63.

25. CaneschiWF, Paiva CC, FradeRL, etal. Useofelasticbandage associated with speech therapy in the control of sialorrhea (hypersalivation). Rev CEFAC 2014;16(5):1558-66.

26. López Tello C, Escuder González S, Oliván Blázquez B, et al. Eficacia del kinesiotaping en la sialorrea en niños con necesidades educativas especiales: un ensayo clínico abierto. Fisioterapia 2012;34(6):275-81.

27. Keklicek H, Uygur F, Yakut Y. Effects of taping the hand in children with cerebral palsy. J Hand Ther 2015;28(1):27-33.

28. Ghalwash AM, El-Shennawy SA, Abd-Elwahab MS Efficacy of adhesive taping in controlling genure curvatum in diplegic children: A pilot study. Egypt J Med Hum Genet 2013;14(2):183-8.

29. Yasukawa A, PatelP, Sisung C. Pilotstudy: Investigating the effects of Kinesio Taping in an acute pediatric rehabilitation setting. Am J Occup Ther 2006;60(1):104-10. 